\title{
Near-Fault Seismic Response Analysis of Bridges Considering Girder Impact and Pier Size
}

\author{
Wenjun An ${ }^{1, *}$, Guquan Song ${ }^{1}$ and Shutong Chen ${ }^{2}$ \\ 1 School of Civil Engineering and Architecture, Nanchang University, Nanchang 330031, China; \\ gqsong@ncu.edu.cn \\ 2 College of Civil Engineering, Jiangxi University of Engineering, Xinyu 330046, China; \\ chenshutong@cumt.edu.cn \\ * Correspondence: wjan@email.ncu.edu.cn
}

Citation: An, W.; Song, G.; Chen, S. Near-Fault Seismic Response Analysis of Bridges Considering Girder Impact and Pier Size. Mathematics 2021, 9, 704. https:// doi.org/10.3390/math9070704

Academic Editor: Zdeněk Kala

Received: 16 February 2021

Accepted: 20 March 2021

Published: 24 March 2021

Publisher's Note: MDPI stays neutral with regard to jurisdictional claims in published maps and institutional affiliations.

Copyright: (c) 2021 by the authors. Licensee MDPI, Basel, Switzerland. This article is an open access article distributed under the terms and conditions of the Creative Commons Attribution (CC BY) license (https:// creativecommons.org/licenses/by/ $4.0 /)$.

\begin{abstract}
Given the influence of near-fault vertical seismic action, we established a girder-springdamping-rod model of a double-span continuous girder bridge and used the transient wave function expansion method and indirect modal function method to calculate the seismic response of the bridge. We deduced the theoretical solution for the vertical and longitudinal contact force and displacement response of the bridge structure under the action of the near-fault vertical seismic excitation, and we analyzed the influence of the vertical separation of the bridge on the bending failure of the pier. Our results show that under the action of a near-fault vertical earthquake, pier-girder separation will significantly alter the bridge's longitudinal displacement response, and that neglecting this separation may lead to the underestimation of the pier's bending damage. Calculations of the bending moment at the bottom of the pier under different pier heights and cross-sectional diameters showed that the separation of the pier and the girder increases the bending moment at the pier's base. Therefore, the reasonable design of the pier size and tensile support bearing in near-fault areas may help to reduce longitudinal damage to bridges.
\end{abstract}

Keywords: bridge; near-fault vertical earthquake; multiple separation; pier size; bending damage

\section{Introduction}

Damage to bridges resulting from earthquakes only affects the traffic, but also affects rescue operations after the disaster. Moreover, it is difficult to repair bridges damaged by an earthquake, which seriously affects the early recovery of transportation [1,2]. In the past, research on bridge damage was mainly concentrated in the horizontal direction [3-5], but in recent years, considering the influence of vertical seismic action on structures, many scholars have conducted research on damage in the vertical direction. Much research has been done on the developments of innovative isolation devices with respect to the vertical earthquake component and the limitation of the maximum horizontal displacement across the device [6,7]. Vertical seismic action changes the axial force of the pier, and the increased axial force may cause the pier to be damaged under compression [8-11]. A number of experiments have been conducted to examine the possible bending and shear damage caused by the axial force on the pier, and it has been proposed that under the action of a vertical earthquake, the fluctuation of the axial force will have an impact on the shear performance of the pier [12-15]. When the axial force of the bridge pier decreases or tensile stress occurs, it will reduce the horizontal shear resistance of the concrete, causing the shear strength of the pier to diminish. The fluctuation of the axial force of the pier will also weaken the bending resistance and ductility of the concrete pier. Under the combined action of horizontal and vertical earthquakes, the pier will be damaged by bending [12,14,15]. For the main beam, the vertical seismic action will increase the mid-span bending moment and cause structural damage [12,16]. 
In previous studies of the influence of the vertical component on the bridge [8-16], the ratio of vertical seismic acceleration to horizontal acceleration did not exceed 2:3. However, with the renewal of seismic monitoring equipment in recent years, more seismic data show that, under the action of near-fault earthquakes, the acceleration amplitude of vertical earthquakes will exceed this ratio. For example, the maximum vertical acceleration recorded during the Northridge earthquake was $1.18 \mathrm{~g}$, and the ratio of vertical seismic acceleration to horizontal acceleration $(\mathrm{V} / \mathrm{H})$ was up to 1.79 [17]. The peak vertical acceleration on the ground was twice the peak lateral acceleration for some records [18]. The nine seismic record curves of the Wenchuan earthquake in Sichuan within $20 \mathrm{~km}$ of the fault had an average $\mathrm{V} / \mathrm{H}$ value of 0.89 and a maximum of 1.2 [19]. Another analysis of the vertical acceleration response spectrum of a near-fault earthquake found that the near-fault earthquake had unique characteristics and that the 2:3 ratio should not be applied [20]. Unlike most building structures, the span of a bridge is large, and vertical vibrations cause large vertical deformation of the main girder. Strong vertical seismic excitation may reduce the contact force of the bridge support [20], weakening the friction between the main girder and the bridge pier. In addition, most bridges in China use plate rubber bearings, and the main girder is placed directly on the support [21]; the support and the main girder lack a tensile connection. When the vertical excitation is excessive, the main girder and pier may become separated. In the 1989 Loms Prieta earthquake [22], the vertical earthquake caused the separation of the main girder and pier, and the collision caused the damage of the bridge deck. This type of damage may cause the main girder to be thrown up under the action of a strong vertical earthquake. When it falls again, it will have a huge collision force with the pier, causing the pier to penetrate the bridge deck. In addition, collisions caused by separation may also cause local damage to the bridge. Tanimura et al. believed that the damage of the support was caused by high stress caused by a collision with the bridge support after the bridge span jumped [23].

Most previous research has been based on constant contact between the girder and the pier, ignoring the possible contact-separation-contact displacement response process of the pier and girder under the action of a near-fault earthquake. The purpose of this research was to establish a theoretical method to research the effect of the vertical separation of piers and girders on bridge displacement. By using the double-span continuous beam model to simulate the seismic response of the bridge, the transient wave function was expanded into a series of eigen-functions [24]. By introducing the indirect wave modal method [25] to solve the collision force response, the theoretical solution of the vertical and longitudinal contact force and displacement response of the girder and piers was obtained. The effect of pier-beam separation on the longitudinal relative displacement of the pier and beam was calculated. Finally, we studied the influence of pier size on the bending failure of the base of the pier.

\section{Structural Model and Wave Equation}

\subsection{Bridge Structure Model}

We considered a double-span continuous beam highway bridge for this research. For the girder, the length of each span of continuous girder is represented by $\mathrm{L}$, the crosssectional area is $A_{b}$, the area moment of inertia is $I_{b}$, the Young's modulus of section is $E_{b}$, and the mass density is $\rho_{b}$. For the piers, the corresponding parameters are $A_{r}, I_{r}, E_{r}$ and $\rho_{r}$. Both ends of the bridge girder were simply supported and the base of the pier was fixed (Figure 1). A single-side vertical spring with zero tensile stiffness and $\mathrm{K}_{\mathrm{c}}$ compressive stiffness was used to approximately model the high damping rubber bearing, and the shear stiffness of the bearing is noted as $K_{v}$. The weight of the main beam is expressed by the uniform load, q. $\mathrm{OA}$ and $\mathrm{OB}$ are the left and right spans of the continuous beam, and $\mathrm{CD}$ are the piers. 


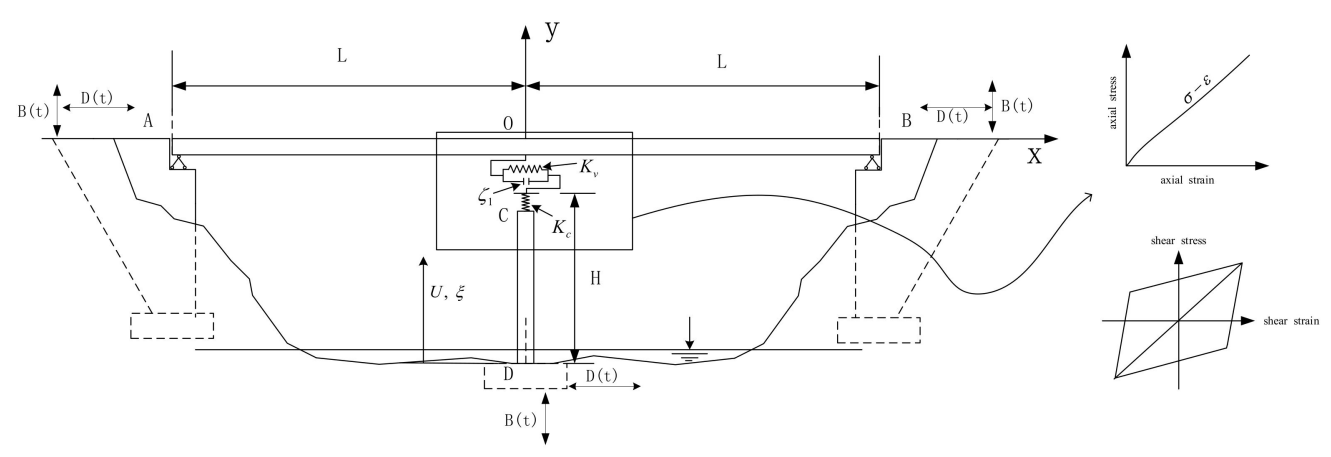

Figure 1. Schematic of double span continuous beam bridge.

The main girder was set as a Bernoulli Euler beam St. Venant rod in the vertical and horizontal directions, respectively, while the pier was set as a St. Venant rod and a Bernoulli Euler beam in the vertical and horizontal directions, respectively. The equivalent vertical seismic excitation, $\mathrm{B}(\mathrm{t})$, and equivalent horizontal seismic excitation, $\mathrm{D}(\mathrm{t})$.

The arrival time of vertical and horizontal seismic excitation varied with distance from the epicenter. To observe the influence of near-fault vertical earthquakes on bridge structures more clearly, it was assumed that the horizontal and vertical excitation of the bridge was consistent. In the transverse direction, an inner stopper is usually provided to limit the displacement of the upper beam body. Therefore, only the effects of vertical and longitudinal earthquakes were considered in this paper. However, setting the inner stopper does not significantly change the parameters of the bridge. For the convenience of modeling, this was ignored. Moreover, although damage to bridges and bearings has been observed in previous earthquakes, to avoid additional complexity and concentrate on the influence of the separation of the girder and pier during pier failure, in this study, the gap between abutment and girder were ignored and material nonlinearity were not considered.

\subsection{Vertical Seismic Response Spectrum}

The bridge was located in an area with a seismic intensity of $8^{\circ}$. The reference peak value of the horizontal seismic acceleration was 510 gal $\left(5.1 \mathrm{~m} / \mathrm{s}^{2}\right)$. To accurately describe the characteristics of vertical earthquakes, the simplified V/H spectra (1) applied in reference [26] were used. The selection of the characteristic values of vertical seismic response spectrum followed [27], and the distances from the epicenter were $3 \mathrm{~km}, 10 \mathrm{~km}$ and $20 \mathrm{~km}$ :

$$
\lambda=V / H= \begin{cases}\alpha & T<0.1 \\ \alpha-\beta(T-0.1) & 0.1 \leq T<0.3 \\ 0.5 & T \geq 0.3\end{cases}
$$

where $T$ is the vertical seismic period, $\alpha$ is the peak value of $\mathrm{V} / \mathrm{H}$, and $\beta$ is the linear attenuation coefficient. When the epicenter distance was $3 \mathrm{~km}, 10 \mathrm{~km}$ and $20 \mathrm{~km}, \alpha=1.5$, $1.4,1.3$ and $\beta=5,4,3$, respectively.

For the sake of simplicity, we used the single harmonic motion instead of seismic excitation, and the acceleration peak value was the seismic excitation acceleration peak value.

\section{Calculation of Bridge Vertical Displacement Response}

In these equations, $Y_{1}(x, t), Y_{2}(x, t)$ represents the deflection of the main beam, and $U(\xi, t)$ is the axial displacement of pier.

The vertical displacement field can be divided into static displacement, rigid body displacement, and dynamic deformation. The vertical displacement of the girder and pier can be derived by

$$
\begin{gathered}
Y(x, t)=Y_{s}(x)+Y_{g}(x, t)+Y_{d}(x, t) \\
U(\xi, t)=U_{s}(\xi)+U_{g}(\xi, t)+U_{d}(\xi, t)
\end{gathered}
$$


The first part of the expression is static displacement. The static solution satisfies the inhomogeneous boundary conditions, which can be expressed as

$$
\begin{gathered}
Y_{1 s}(x)=\left[q\left(-5 L^{4}+6 L^{2} x^{2}-x^{4}\right)-2 F_{c}\left(2 L^{3}-x^{3}-3 x^{2} L\right)\right] / 24 E_{b} I_{b} \\
Y_{2 s}(x)=\left[q\left(-5 L^{4}+6 L^{2} x^{2}-x^{4}\right)-2 F_{c}\left(2 L^{3}+x^{3}-3 x^{2} L\right)\right] / 24 E_{b} I_{b} \\
U(\xi)=F_{c} \xi / E_{r} A_{r}
\end{gathered}
$$

where $F_{c}$ is the axial pressure of the initial girder and the support. This can be expressed as

$$
F_{c}=\frac{-5 q L^{4}}{24 E_{b} I_{b} H / E_{r} A_{r}+24 E_{b} I_{b} / K_{c}+4 L^{3}}
$$

The second part is the rigid body displacement, which can be expressed as

$$
Y_{1 g}(x, t)=Y_{2 g}(x, t)=U_{g}(\xi, t)=B(t)
$$

The equations of motion can be described as follows:

$$
\begin{gathered}
O A: \frac{\partial^{2}\left(E_{b} I_{b} \partial^{2} Y_{1}(x, t) / \partial x^{2}\right)}{\partial x^{2}}+\rho A_{b} \frac{\partial^{2} Y_{1}(x, t)}{\partial t^{2}}+q=0 \\
O B: \frac{\partial^{2}\left(E_{b} I_{b} \partial^{2} Y_{2}(x, t) / \partial x^{2}\right)}{\partial x^{2}}+\rho A_{b} \frac{\partial^{2} Y_{2}(x, t)}{\partial t^{2}}+q=0 \\
C D: E_{r} A_{r} \frac{\partial^{2} U(\xi, t)}{\partial^{2} \xi}-\rho A_{r} \frac{\partial^{2} U(\xi, t)}{\partial t^{2}}=0
\end{gathered}
$$

The third part is dynamic displacement, which can be expanded as an infinite series of wave mode products:

$$
\begin{gathered}
Y_{1 d}(x, t)=\sum_{n=1}^{\infty} \varphi_{n b 1}(x) q_{n}(t), Y_{2 d}(x, t)=\sum_{n=1}^{\infty} \varphi_{n b 2}(x) q_{n}(t) \\
U_{d}(\xi, t)=\sum_{n=1}^{\infty} \varphi_{n r}(\xi) q_{n}(t)
\end{gathered}
$$

where $\varphi_{n b 1}, \varphi_{n b 2}$ is the bending wave function of the girder, $\varphi_{n r}$ is the longitudinal wave function of the pier, and $q_{n}(t)$ is the time function. Dynamic displacement satisfies the wave equation, continuity condition, equilibrium differential equation and force boundary condition.

\subsection{Theoretical Solution of Displacement Response of Bridge in Vertical Contact Stage}

The wave mode function was solved by the characteristic equations. The characteristic equations of the main girder and pier were as follows:

$$
\begin{array}{cc}
O A: & a^{2} \varphi_{n b 1}{ }^{(4)}(x)-\omega_{n}^{2} \varphi_{n b 1}(x)=0 \\
O B: & a^{2} \varphi_{n b 2}(4)(x)-\omega_{n}^{2} \varphi_{n b 2}(x)=0 \\
C D: & c^{2} \varphi_{n r}(2)(\xi)+\omega_{n}^{2} \varphi_{n r}(\xi)=0
\end{array}
$$

where $\omega_{n}(n=1,2,3, \cdots \cdots)$ is the natural frequency of the bridge structure, $a_{1}=\sqrt{E_{b} I_{b} / \rho A_{b}}$ is the coefficient related to the beam flexural wave speed, and $c_{1}=\sqrt{E_{r} / \rho}$ is the rod phase speed.

Flexural wave modes of the main girder and the longitudinal wave of pier can be described as

$$
\begin{gathered}
\varphi_{n b 1}(x)=A_{1} \sin k_{b n} x+B_{1} \cos k_{b n} x+C_{1} \sinh k_{b n} x+D_{1} \cosh k_{b n} x \\
\varphi_{n b 2}(x)=A_{2} \sin k_{b n} x+B_{2} \cos k_{b n} x+C_{2} \sinh k_{b n} x+D_{2} \cosh k_{b n} x \\
\varphi_{n r}=E \sin k_{r n} \xi+F \cos k_{r n} \xi
\end{gathered}
$$

where $k_{b n}$ and $k_{r n}$ are the wave numbers of flexural wave and longitudinal wave, respectively. $A_{1}, B_{1}, C_{1}, D_{1}, A_{2}, B_{2}, C_{2}, D_{2}, E, F$ are the coefficients of the flexural wave and the longitudinal wave. 
The boundary conditions of the characteristic equation are as follows:

$$
\begin{gathered}
\varphi_{n b 1}(-L)=0, \varphi_{n b 2}(L)=0, \varphi_{n r}(0)=0 \\
\varphi^{\prime \prime}{ }_{n b 1}(-L)=0, \varphi^{\prime \prime}{ }_{n b 2}(L)=0
\end{gathered}
$$

The continuity condition of feature direction are as follows:

$$
\begin{gathered}
\varphi_{n b 1}(0)=\varphi_{n b 2}(0), \varphi_{n b 1}^{\prime}(0)=\varphi_{n b 2}^{\prime}(0), \varphi^{\prime \prime}{ }_{n b 1}(0)=\varphi^{\prime \prime}{ }_{n b 2}(0) \\
\varphi_{n b 1}(0)=\varphi_{n r}(H)+\frac{E_{r} A_{r} \varphi_{n r}^{\prime}(H)}{K_{c}} \\
E_{b} I_{b}\left(\varphi^{\prime \prime \prime}{ }_{n b 1}(0)-\varphi^{\prime \prime \prime}{ }_{n b 2}(0)\right)=E_{r} A_{r} \varphi^{\prime}{ }_{n r}(H)
\end{gathered}
$$

The orthogonal consistency of bending wave and longitudinal wave can be obtained by Equations (9) and (10):

$$
\begin{gathered}
\left(\omega_{m}^{2}-\omega_{n}^{2}\right)\left[\int_{-L}^{0} \rho A_{b} \varphi_{m b 1} \varphi_{n b 1} d x+\int_{0}^{L} \rho A_{b} \varphi_{m b 2} \varphi_{n b 2} d x+\int_{0}^{H} \rho A_{r} \varphi_{m r} \varphi_{n r} d \xi\right] \\
=\int_{-L}^{0} a_{1}^{2} \rho A_{b}\left(\varphi_{m b 1}^{(4)} \varphi_{n b 1}-\varphi_{n b 1}^{(4)} \varphi_{m b 1}\right) d x+\int_{0}^{L} a_{1}^{2} \rho A_{b}\left(\varphi_{m b 2}^{(4)} \varphi_{n b 2}-\varphi_{n b 2}^{(4)} \varphi_{m b 2}\right) d x \\
+\int_{0}^{H} \rho A_{r}\left(\varphi^{\prime \prime}{ }_{n r} \varphi_{m r}-\varphi^{\prime \prime}{ }_{m r} \varphi_{n r}\right) d \xi=0 \\
\int_{-L}^{0} \rho A \varphi_{m b 1} \varphi_{n b 1} d x+\int_{0}^{L} \rho A \varphi_{m b 2} \varphi_{n b 2} d x+\int_{0}^{H} \rho A_{r} \varphi_{m r} \varphi_{n r} d \xi=\delta_{m n}
\end{gathered}
$$

By introducing Equations (10) and (11) into Equation (9), the wave functions of the bridge structure can be obtained as follows:

$$
\begin{gathered}
\varphi_{n b 1}(x)=M_{n} A_{n}\left(-\frac{\sin k_{b n}(x+L)}{\cos k_{b n} L}+\frac{\sinh k_{b n}(x+L)}{\cosh k_{b n} L}\right) \\
\varphi_{n b 2}(x)=M_{n} A_{n}\left(\frac{\sin k_{b n}(x-L)}{\cos k_{b n} L}-\frac{\sinh k_{b n}(x-L)}{\cosh k_{b n} L}\right) \\
\varphi_{n r}(\xi)=A_{n} \sin k_{r n} \xi
\end{gathered}
$$

By introducing Equation (14) into Equation (11), $M_{n}$ and $A_{n}$ become

$$
\begin{gathered}
M_{n}=\left[\sin \left(k_{r n} H\right)+\frac{E_{r} A_{r} k_{r n} \cos \left(k_{r n} H\right)}{K_{c}}\right] /\left[\frac{\sinh \left(k_{b n} L\right)}{\cosh \left(k_{b n 1} L\right)}-\frac{\sin \left(k_{b n} L\right)}{\cos \left(k_{b n} L\right)}\right] \\
=\frac{E_{r} A_{r} k_{r n} \cos \left(k_{r n} H\right)}{4 E_{b} A_{b} k_{b n}^{3}} \\
A_{n}^{-2}=M_{n}^{2}\left\{\begin{array}{l}
\int_{-L}^{0} \rho A_{b}\left[-\frac{\sin k_{b n}(x+L)}{\cos k_{b n} L}+\frac{\sinh k_{b n}(x+L)}{\cosh k_{b n} L}\right]^{2} d x \\
+\int_{0}^{L} \rho A_{b}\left[\frac{\sin k_{b n}(x-L)}{\cos k_{b n} L}-\frac{\sinh k_{b n}(x-L)}{\cosh k_{b n} L}\right]^{2} d x \\
\int_{0}^{L} \rho A_{r} \sin ^{2}\left(k_{r n} \xi\right) d \xi
\end{array}\right\} \\
=M_{n}^{2} \rho A_{b}\left(\frac{L}{2 \cos ^{2}\left(k_{b n} L\right)}-\frac{L}{2 \cosh ^{2}\left(k_{b n} L\right)}-\frac{3 \tan \left(k_{b n} H\right)}{2 k_{b n}}+\frac{3 \tanh \left(k_{b n} H\right)}{2 k_{b n}}\right) \\
+\rho A_{r}\left(\frac{H}{2}-\frac{\sin \left(2 k_{r n} H\right)}{8 k_{r n}}\right)
\end{gathered}
$$

Through the orthogonality condition, the time function $q_{n}(t)$ differential equation of the bridge structure can be obtained:

$$
\omega_{n}^{2} q_{n}(t)+2 \zeta \omega_{n} \dot{q}_{n}(t)+\ddot{q}_{n}(t)=\ddot{Q}_{n}(t)
$$

where

$$
Q_{n}(t)=\left\{\begin{array}{l}
-\int_{-}^{0} \rho A_{b} \varphi_{n b 1}(x)\left(Y_{1 s}(x)+Y_{1 g}(x, t)\right) \varphi_{n b 1}(x) d x \\
-\int_{0}^{L} \rho A_{b} \varphi_{n b 2}(x)\left(Y_{2 s}(x)+Y_{2 g}(x, t)\right) \varphi_{n b 2}(x) d x \\
-\int_{0}^{H} \rho A_{r} \varphi_{n r}(\xi)\left(U_{s}(\xi)+U_{g}(\xi, t)\right) d \xi
\end{array}\right\}
$$


By Laplace transformation, $q_{n}(t)$ can be obtained as follows:

$$
\begin{gathered}
q_{n}(t)=e^{-\zeta_{2} \omega_{n} t}\left(q_{n}(0) \cos \omega_{d} t+\frac{\dot{q}_{n}(0)+\zeta_{2} \omega_{n} q_{n}(0)}{\omega_{d}} \sin \omega_{d} t\right) \\
+\frac{1}{\omega_{d}} \int_{0}^{t} e^{-\zeta_{2} \omega_{n} \tau} \ddot{Q}_{n}(\tau) \sin \left(\omega_{d}(t-\tau)\right) d \tau
\end{gathered}
$$

where

$$
\begin{gathered}
q_{n}(0)=\int_{-L}^{0} \rho A_{b} \varphi_{n b 1}(x) Y_{10}(x) d x+\int_{0}^{L} \rho A_{b} \varphi_{n b 2}(x) Y_{20}(x) d x \\
\quad+\int_{0}^{H} \rho A_{r} \varphi_{n r}(\xi) U_{0}(\xi) d \xi+Q_{n}(0) \\
\dot{q}_{n}(0)=\int_{-L}^{0} \rho A_{b} \varphi_{n b 1}(x) \dot{Y}_{10}(x) d x+\int_{0}^{L} \rho A_{b} \varphi_{n b 2}(x) \dot{Y}_{20}(x) d x \\
\quad+\int_{0}^{H} \rho A_{r} \varphi_{n r}(\xi) \ddot{U}_{0}(\xi) d \xi+\dot{Q}_{n}(0)
\end{gathered}
$$

In Equation (18), $\omega_{d}=\sqrt{1-\zeta_{2}^{2}} \omega_{n}$.

\subsection{Corresponding Theoretical Solution of Bridge Vertical Separation Stage Displacement}

During the separation process, the beam and the rod do not interact and move at their own characteristic frequencies of $\omega_{n b}$ and $\omega_{n r}$, respectively.

The displacement response of the main girder and pier can be decomposed into static displacement, rigid displacement and dynamic deformation, and the main beam does not need to be decomposed into two segments.

$$
\begin{gathered}
\bar{Y}(x, t)=\bar{Y}_{s}(x)+\bar{Y}_{g}(x, t)+\bar{Y}_{d}(x, t) \\
\bar{U}(\xi, t)=\bar{U}_{s}(\xi, t)+\bar{U}_{g}(\xi, t)+\bar{U}_{d}(\xi, t)
\end{gathered}
$$

The vertical static displacement and rigid displacement of the bridge structure are as follows:

$$
\begin{gathered}
\bar{Y}_{s}(x)=q\left(-5 L^{4}+6 L^{2} x^{2}-x^{4}\right) / 24 E_{b} I_{b}, \bar{U}_{s}(\xi)=0 \\
\bar{Y}_{g}(x, t)=\bar{U}_{g}(\xi, t)=B(t)
\end{gathered}
$$

The wave equations of girder $\mathrm{AB}$ and pier $\mathrm{CD}$ can be described as

$$
\begin{gathered}
A B: \frac{\partial^{2}\left(E_{b} I_{b} \partial^{2} \bar{Y}(x, t) / \partial x^{2}\right)}{\partial x^{2}}+\rho A_{b} \frac{\partial^{2} \bar{Y}(x, t)}{\partial t^{2}}+q=0 \\
C D: E_{r} A_{r} \frac{\partial^{2} \bar{U}(\zeta, t)}{\partial^{2} \tilde{\zeta}}-\rho A_{r} \frac{\partial^{2} \bar{U}(\tilde{s}, t)}{\partial t^{2}}=0
\end{gathered}
$$

The wave mode functions of the main girder and pier are as follows:

$$
\begin{gathered}
\bar{\varphi}_{n b}(x)=A_{3} \sin \bar{k}_{b n} x+B_{3} \cos \bar{k}_{b n} x+C_{3} \sinh \bar{k}_{b n} x+D_{3} \cosh \bar{k}_{b n} x \\
\bar{\varphi}_{n r}=E_{2} \sin \bar{k}_{r n} \xi+F_{2} \cos \bar{k}_{r n} \xi
\end{gathered}
$$

where $A_{3}, B_{3}, C_{1}, D_{3}, E_{2}, F_{2}$ are the coefficients of the flexural wave and the longitudinal wave.

The boundary conditions of the characteristic equation are as follows:

$$
\begin{gathered}
\bar{\varphi}_{n b}(-L)=0, \bar{\varphi}_{n b}(L)=0, \bar{\varphi}_{n r}(0)=0 \\
{\overline{\varphi^{\prime \prime}}}_{n b}(-L)=0, \bar{\varphi}^{\prime \prime}{ }_{n b}(L)=0
\end{gathered}
$$

The wave functions of the bridge structure can be obtained as follows:

$$
\begin{gathered}
\bar{\varphi}_{n b}(x)=A_{n b} \sin \bar{k}_{b n}(x+L) \\
\bar{\varphi}_{n r}(\xi)=A_{n r} \sin \bar{k}_{r n} \xi
\end{gathered}
$$

For the main girder and pier, the wave numbers are

$$
\bar{k}_{b n}=\sqrt{\omega_{b n} / a}=n \pi / 2 L, \bar{k}_{r n}=\omega_{r n} / c=(2 n-1) \pi / 2 H
$$


Based on the orthogonality of the wave mode function, the coefficient can be obtained as

$$
A_{n b}=1 / \sqrt{\rho A_{b} L}, A_{n r}=2 / \sqrt{\rho A_{r} H}
$$

If the separation contact phenomenon occurs many times, it can be assumed that $t^{*}=t-t_{2 k}$ is the time variable of the $\mathrm{k}$-th collision, and that $t^{*}=t-t_{2 k+1}$ is the time variable of the $\mathrm{k}$-th separation. $t^{-}$is the end time of a process at the point of state change time, and $t^{+}$is the start time of the next process.

In the k-th separation process, the dynamic displacement responses of main girder and pier are as follows:

$$
\begin{aligned}
q_{n b}\left(t^{*}\right) & =e^{-\zeta_{2} \omega_{b 1} t^{*}}\left(q_{1 b}\left(t_{2 k+1}^{-}\right) \cos \omega_{b 1} t^{*}+\frac{\dot{q}_{n}\left(t_{2 k+1}^{-}\right)+\zeta_{2} \omega_{b 1} q_{n b}(0)}{\omega_{b 1}} \sin \omega_{b 1} t^{*}\right) \\
& +\frac{1}{\omega_{b d}} \int_{0}^{t^{*}} e^{-\zeta_{2} \omega_{b n} \tau} \ddot{Q}_{b n}(\tau) \sin \left(\omega_{b d}\left(t^{*}-\tau\right)\right) d \tau \\
q_{n r}\left(t^{*}\right) & =e^{-\zeta_{2} \omega_{r 1} t^{*}}\left(q_{1 r}\left(t_{2 k+1}^{-}\right) \cos \omega_{b 1} t^{*}+\frac{\dot{q}_{n}\left(t_{2 k+1}^{-}\right)+\zeta_{2} \omega_{r 1} q_{n r}(0)}{\omega_{r 1}} \sin \omega_{r 1} t^{*}\right) \\
& +\frac{1}{\omega_{r d}} \int_{0}^{t^{*}} e^{-\zeta_{2} \omega_{r n} \tau} \ddot{Q}_{r n}(\tau) \sin \left(\omega_{r d}\left(t^{*}-\tau\right)\right) d \tau
\end{aligned}
$$

The initial displacement and velocity of the girder and pier structure are considered only by the first mode. $\omega_{b 1}$ and $\omega_{r 1}$ are the first natural vibration frequencies of beams and piers. $\omega_{b d}$ and $\omega_{r d}$ consider the natural frequencies of main girder and pier under damping. By considering the residual velocity and deformation of the last process, the contact separation process is solved continuously.

\subsection{Corresponding Theoretical Solution of Bridge Displacement in the Vertical Collision Stage}

When the relative displacement between the girder and the pier is less than zero, it is considered that the girder and the pier are in contact again. At the moment of collision contact, the overall frequency of the bridge cannot be calculated. The use of resonance frequency calculation will produce large dispersion, and it is difficult to ensure the convergence of the calculation results. In the process of vertical impact, the dynamic deformation after the contact collision can be divided into the impact force deformation, $X_{F}$, and the dynamic wave deformation, $X_{z}$. The indirect mode superposition method [24] was used to calculate the structural displacement under the impact force. The initial contact time was calculated as $Y_{s}+Y_{d}=U_{s}+U_{d}=0$.

The collision between the main beam and pier was considered an elastic impact problem, ignoring the plasticity of the structure. In the subsequent vertical collision process, the main beam and the bridge pier have no vertical contact force at the initial moment, and the static displacement of the main beam and the bridge pier is zero. It can be concluded that the dynamic displacement of the bridge at the initial moment is

$$
Y_{1 d}\left(0, t_{2 k}^{+}\right)=Y_{2 d}\left(0, t_{2 k}^{+}\right)=U_{d}\left(0, t_{2 k}^{+}\right)=0
$$

The collision displacement of the bridge structure can be calculated as

$$
\begin{aligned}
& Y_{F}=\frac{\sum_{i=1}^{\infty} \bar{\varphi}_{n b}(0) \dot{q}_{b n}\left(t_{2 k}^{-}\right)}{\omega_{n b}} \sin \omega_{n b} t-\sum_{n=1}^{\infty} \bar{\varphi}_{n b}(x) \int_{t_{2 k}}^{t^{*}} Q_{n b} h_{n b} d \tau \\
& U_{F}=\frac{\sum_{i=1}^{\infty} \bar{\varphi}_{n r}(0) \dot{q}_{r n}\left(t_{2 k}^{-}\right)}{\omega_{n r}} \sin \omega_{n r} t+\sum_{n=1}^{\infty} \bar{\varphi}_{n r}(\xi) \int_{t_{2 k}}^{t^{*}} Q_{n r} h_{n r} d \tau
\end{aligned}
$$


where $Q_{n b}=F_{p} \bar{\varphi}_{n b}\left(x_{0}\right), Q_{n r}=F_{p} \bar{\varphi}_{n r}\left(\xi_{0}\right)$ is the generalized collision force; $x_{0}$ and $\xi_{0}$ are the coordinate of the collision point of the main beam and pier, respectively; and $F_{p}$ is the impact force. The positive and negative signs in Equation (27) denote the relationship between the force and displacement direction, respectively.

$$
\begin{gathered}
h_{n b}=\frac{1}{M_{n b} \omega_{n b}} \sin \omega_{n b}(t-\tau), h_{n r}=\frac{1}{M_{n r} \omega_{n r}} \sin \omega_{n r}(t-\tau) \\
M_{n b}=\int_{-L}^{L} \rho A \bar{\varphi}_{n b}^{2}(x) d x, M_{n r}=\int_{0}^{H} \rho A_{r} \bar{\varphi}_{n r}^{2}(\xi) d \xi
\end{gathered}
$$

where $h_{n b}$ and $h_{n r}$ are impulse response functions of beam and pier respectively. $M_{n b}, M_{n r}$ are modal masses.

At the impact contact stage, the displacement of the girder and the pier differs. The impact force is $F_{p}=0$ when the girder and pier are separated, and the collision force is $F_{p}>0$. At the point of impact, the displacement response is as follows:

$$
Y_{F}(0, t)-U_{F}(H, t)=F_{p}(t) / K_{c}
$$

By introducing Equation (30) into Equation (32), the vertical load, $F_{p}$, and the collision contact part of the bridge structure displacement, $Y_{F}, U_{F}$, can be calculated using the step-by-step integration method.

The partial time function of dynamic deformation is as follows:

$$
q_{n}(t)=\frac{1}{\omega_{n}} \int_{t_{2 k}}^{t^{*}} \ddot{Q}_{n}(0) \sin \left(\omega_{n}(t-\tau)\right) d \tau
$$

The dynamic deformation of bridge can be expressed as follows:

$$
\Upsilon_{d 1}=\sum_{n=1}^{\infty} \varphi_{n b 1}(x) q_{n}(t), Y_{d 2}=\sum_{n=1}^{\infty} \varphi_{n b 2}(x) q_{n}(t), U_{d}=\sum_{n=1}^{\infty} \varphi_{n r}(\xi) q_{n}(t)
$$

\section{Calculation of the Bridge's Longitudinal Displacement Response}

Referring to the process of solving the vertical displacement response of the bridge, the wave mode equations of the girder and pier in the longitudinal direction can be obtained as follows:

$$
\begin{gathered}
\varphi_{n b 1}(x)=A_{n} \sin k_{b n} x+A_{n} \tan k_{b n} L \cos k_{b n} x \\
\varphi_{n b 2}(x)=-A_{n} \sin k_{b n} x+A_{n} \tan k_{b n} L \cos k_{b n} x \\
\varphi_{n r}(\xi)=M_{1} A_{n}\left(\sin k_{r n} \xi-\sinh k_{r n} \xi\right)+M_{2} A_{n}\left(\cos k_{r n} \xi-\cosh k_{r n} \xi\right)
\end{gathered}
$$

We can refer to Equation (14) to solve $M_{1}, M_{2}, A_{n}$.

Considering the bearing damping, the time function of the bridge displacement response is

$$
\begin{gathered}
q_{n}\left(t^{*}\right)=e^{-\left(\zeta_{1}+\zeta_{2}\right) \omega_{n} t^{*}}\left(q_{n}(0) \cos \omega_{d} t^{*}+\frac{\dot{q}_{n}(0)+q_{n}(0) \omega_{n}\left(\zeta_{1}+\zeta_{2}\right)}{\omega_{d}} \sin \omega_{d} t^{*}\right) \\
+\frac{1}{\omega_{d}} \int_{0}^{t^{*}} \ddot{Q}_{n}(\tau) e^{-\left(\zeta_{1}+\zeta_{2}\right) \omega_{n}(t-\tau)} \sin \omega_{d}\left(t^{*}-\tau\right) d \tau
\end{gathered}
$$

where $\omega_{d}=\sqrt{\left[1-\left(\zeta_{1}+\zeta_{2}\right)^{2}\right.} \omega_{n}$.

During the separation process, the wave mode functions of the main beam and bridge pier are as follows:

$$
\begin{gathered}
\bar{\varphi}_{n b}(x)=A_{n b} \sin \bar{k}_{b n}(x+L) \\
\left.\bar{\varphi}_{n r}(\xi)=A_{n r}\left(\cosh \bar{k}_{r n} \xi-\cos \bar{k}_{r n} \xi\right)+M_{3}\left(\sinh \bar{k}_{r n} \xi-\sin \bar{k}_{r n} \xi\right)\right)
\end{gathered}
$$

The time function of the girder and pier is consistent with Equation (27). The calculation process of the longitudinal displacement response of the bridge in the collision process 
is the same as the vertical calculation process, except that $\zeta_{2}$ in Equations (29) and (33) is changed to $\zeta_{1+2}$.

\section{Numerical Simulation and Analysis}

We used a typical highway bridge in China as a case study to analyze the results of the calculation. The bridge is a two-span continuous prestressed concrete box bridge. Each pier is composed of two circular concrete columns with spiral stirrups and longitudinal bars. Figure 2 shows the longitudinal section of the bridge and the reinforcement of the pier.

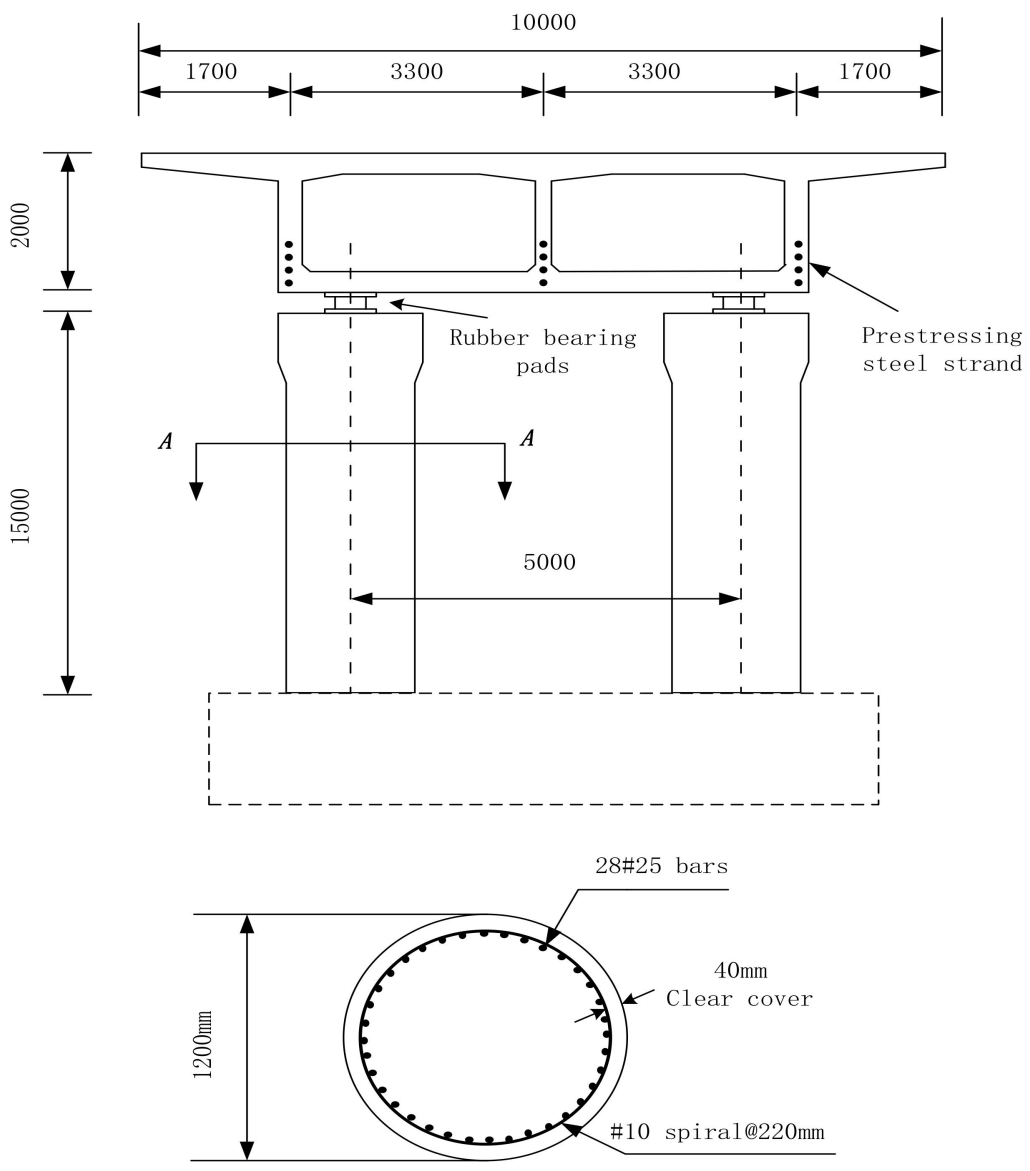

Figure 2. Dimensions and details of the bridge elevation and cross-section.

To simplify the analysis, the equivalent parameters of the bridge can be calculated according to specifications for the design of highway reinforced concrete and prestressed concrete bridges and culverts in China. According to the specification, the equivalent cross-sectional area of the bridge pier is $A_{r}=A_{r c}+\left(\alpha_{y}-1\right) A_{r y}$, the equivalent Young's modulus of bridge pier is $E_{r}=\left(E_{r c} A_{r c}+E_{r y} A_{r y}\right) /\left(A_{r c}+A_{r y}\right)$, and the equivalent moment of inertia of the bridge pier is $I_{r}=I_{r c}+I_{r y}$. The equivalent section area of the main beam is $A_{b}=A_{b c}+\left(\alpha_{y}-1\right) A_{b y}+\left(\alpha_{p}-1\right) A_{b p}$, and the equivalent Young's modulus of the main beam is $E_{b}=\left(E_{b c} A_{b c}+E_{b y} A_{b y}+E_{b p} A_{b p}\right) /\left(A_{b c}+A_{b y}+A_{b p}\right)$. The equivalent section moment of inertia of the main beam is $I_{b}=I_{b c}+I_{b y}+I_{b p}$. A round lead rubber bearing is used between the main girder and the piers. The coefficients of the main girder and piers are shown in Table 1. 
Table 1. The parameters of the bridge girder and pier.

\begin{tabular}{|c|c|c|c|}
\hline \multicolumn{2}{|c|}{ Parameter of Bridge Girder } & \multicolumn{2}{|c|}{ Parameter of Bridge Pier } \\
\hline Single span length & $\mathrm{L}=38 \mathrm{~m}$ & Single span length & $\mathrm{H}=15 \mathrm{~m}$ \\
\hline Mass density & $\rho=2600 \mathrm{~kg} / \mathrm{m}^{3}$ & Mass density & $\rho=2600 \mathrm{~kg} / \mathrm{m}^{3}$ \\
\hline Concrete section area & $\mathrm{A}_{\mathrm{c}}=6.06 \mathrm{~m}^{2}$ & Concrete section area & $\mathrm{A}_{\mathrm{c}}=2.26 \mathrm{~m}^{2}$ \\
\hline $\begin{array}{l}\text { Moment of inertia of } \\
\text { concrete section }\end{array}$ & $\mathrm{I}_{\mathrm{C}}=3.409 \mathrm{~m}^{4}$ & $\begin{array}{l}\text { Moment of inertia of } \\
\text { concrete section }\end{array}$ & $\mathrm{I}_{\mathrm{C}}=0.2036 \mathrm{~m}^{4}$ \\
\hline $\begin{array}{l}\text { Young's modulus of } \\
\text { concrete }\end{array}$ & $\mathrm{E}_{\mathrm{C}}=34.5 \mathrm{GPa}$ & $\begin{array}{l}\text { Young's modulus of } \\
\text { concrete }\end{array}$ & $\mathrm{E}_{\mathrm{c}}=34.5 \mathrm{GPa}$ \\
\hline $\begin{array}{c}\text { Sectional area of } \\
\text { longitudinal } \\
\text { reinforcement }\end{array}$ & $\mathrm{A}_{\mathrm{y}}=0.047 \mathrm{~m}^{2}$ & $\begin{array}{c}\text { Sectional area of } \\
\text { longitudinal } \\
\text { reinforcement }\end{array}$ & $\mathrm{A}_{\mathrm{y}}=0.0274 \mathrm{~m}^{2}$ \\
\hline $\begin{array}{l}\text { Moment of inertia of } \\
\text { steel bar section }\end{array}$ & $\mathrm{I}_{\mathrm{y}}=0.1925 \mathrm{~m}^{4}$ & $\begin{array}{l}\text { Moment of inertia of } \\
\text { steel bar section }\end{array}$ & $\mathrm{I}_{\mathrm{y}}=0.0044 \mathrm{~m}^{4}$ \\
\hline $\begin{array}{l}\text { Young's modulus of } \\
\text { longitudinal } \\
\text { reinforcement }\end{array}$ & $\mathrm{E}_{\mathrm{y}}=200 \mathrm{GPa}$ & $\begin{array}{l}\text { Young's modulus of } \\
\text { longitudinal } \\
\text { reinforcement }\end{array}$ & $\mathrm{E}_{\mathrm{y}}=200 \mathrm{GPa}$ \\
\hline $\begin{array}{c}\text { Section area of } \\
\text { prestressed steel bar }\end{array}$ & $A_{p}=0.0269 m^{2}$ & & \\
\hline $\begin{array}{l}\text { Moment of inertia of } \\
\text { prestressed steel bar } \\
\text { section }\end{array}$ & $\mathrm{I}_{\mathrm{p}}=0.076 \mathrm{~m}^{4}$ & & \\
\hline $\begin{array}{l}\text { Young's modulus of } \\
\text { prestressed steel }\end{array}$ & $\mathrm{E}_{\mathrm{p}}=200 \mathrm{GPa}$ & & \\
\hline
\end{tabular}

Based on a large number of theoretical and experimental studies, the hysteresis curve of the rubber bearing was elongated in the vertical direction and the vertical stiffness was approximately set to a constant. For the convenience of calculation, we assumed that the rubber bearing stiffness was $\mathrm{K}_{\mathrm{c}}=2 \times 10^{9} \mathrm{~N} / \mathrm{m}$ (total for the pair of bearings). In the horizontal direction, the high damping rubber bearing was assumed to be a spring damping model, the shear stiffness of the rubber bearing was calculated as $\mathrm{K}_{\mathrm{v}}=3.6 \times 10^{6} \mathrm{~N} / \mathrm{m}$ and the damping was taken as $\zeta_{1}=20 \%$. The damping coefficient of the bridge was set to $\zeta_{2}=2 \%$.

\subsection{Influence of Bridge Separation on Relative Displacement of the Piers and Girder}

Since the natural period of the bridge is inconsistent in the vertical and horizontal directions, the seismic excitation period selected in this paper was close to the horizontal and vertical natural periods for analysis. To ensure the accuracy of the calculation, the appropriate time-step increments must be selected. For the selection of time-step increments, it was necessary to clearly express the characteristics transmitted in the girder and pier, so a small time-step increase was required for analysis. The longitudinal wave velocity of the bridge pier was $c_{r}=\sqrt{E_{r} / \rho_{r}}=3492 \mathrm{~m} / \mathrm{s}$, and the bending wave velocity was $a_{r}=\sqrt{E_{r} I_{r} / \rho_{r} A_{r}}=1060 \mathrm{~m} / \mathrm{s}$. The maximum time-step increments were smaller than the time for the bending and longitudinal waves to travel across the entire pier, $\Delta \mathrm{t}<\frac{\mathrm{L}}{\mathrm{c}_{\mathrm{r}}}=0.0043 \mathrm{~s}$. Hence, time-step increments of $0.001 \mathrm{~s}$ were used. Another parameter considered in this study was the modal cut-off number of the wave. Considering the influence of damping on high-frequency vibration, the number of modes selected in this study was $n=5$.

Figure 3 shows the calculation flow chart of the vertical displacement of the bridge in the case of possible vertical separation. The calculation time was $2 \mathrm{~s}$. By recording the time of each separation and recontact in the vertical calculation and substituting it into the longitudinal seismic calculation, the longitudinal displacement response of the bridge considering the separation condition was obtained. 


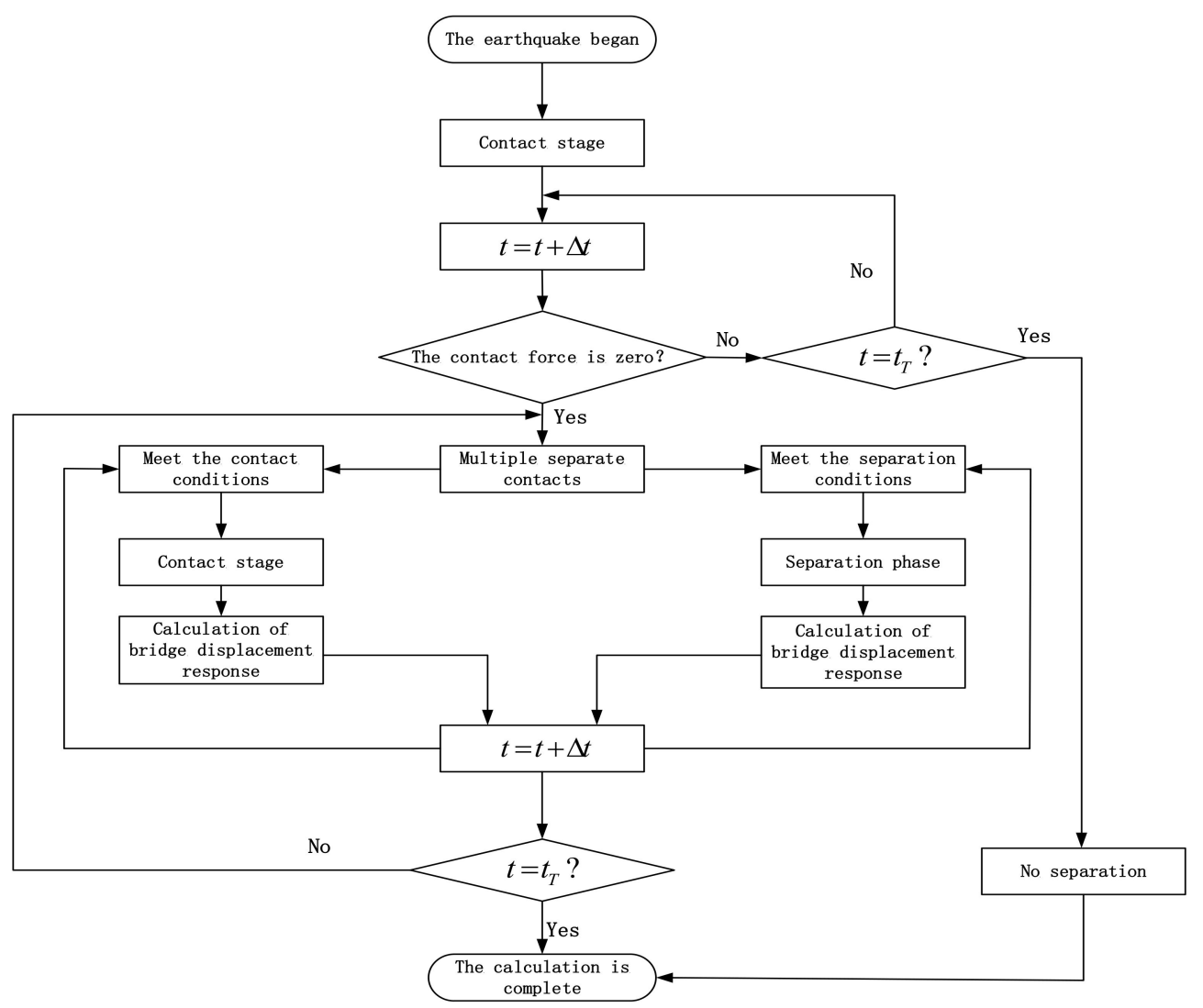

Figure 3. Flow chart showing bridge vertical displacement calculation procedure.

To consider the impact of resonance on the bridge's structure, the selected seismic excitation periods were close to the horizontal natural vibration period, $T_{s}$, and the vertical natural vibration period, $T_{v}$, of the bridge. Figure 4 shows the longitudinal displacement response of the bridge under two different seismic excitation cycles. When the earthquake excitation period was $\mathrm{T}=0.35 \mathrm{~s}$, it was close to the bridge longitudinal natural vibration period, $T_{s}$. When the earthquake excitation period was $\mathrm{T}=0.22 \mathrm{~s}$, it was close to the vertical natural vibration period, $T_{v}$, of the bridge. Without considering the impact of the vertical earthquake, the maximum longitudinal relative displacement of the pier and girder was $34.2 \mathrm{~mm}$ when $T \approx T_{s}$, and the maximum longitudinal relative displacement of the pier beam was $19.1 \mathrm{~mm}$ when $T \approx T_{v}$. The longitudinal displacement of the pier was mainly due to the longitudinal resonance of the bridge.

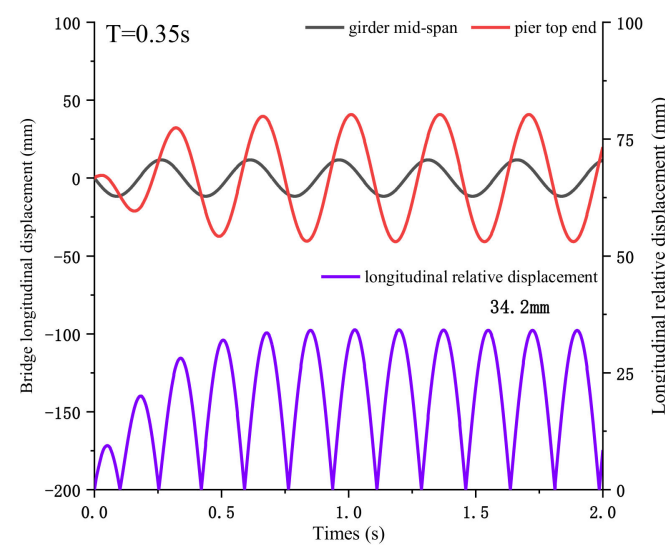

(a)

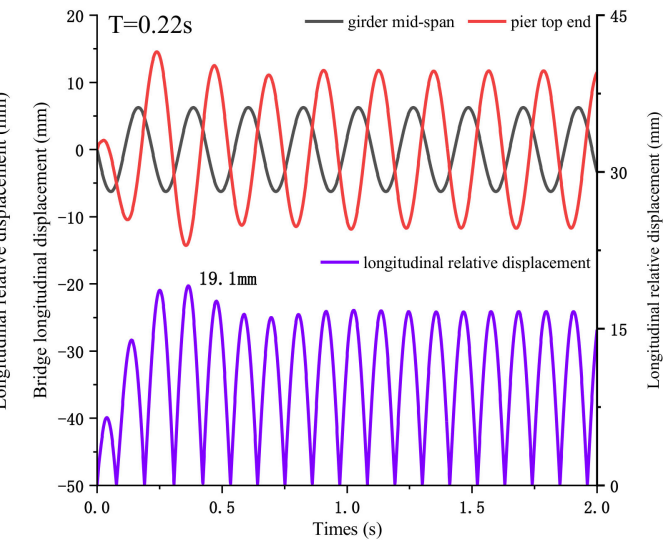

(b)

Figure 4. Bridge longitudinal displacement response: $(\mathbf{a}) \mathrm{T}=0.35 \mathrm{~s} ;(\mathbf{b}) \mathrm{T}=0.22 \mathrm{~s}$. 
Under the action of near-fault earthquakes, the $\mathrm{V} / \mathrm{H}$ amplitude ratio may exceed $2 / 3$ as specified in the code. When the seismic excitation period is close to the vertical natural vibration period of the bridge, it may cause the girder and pier to separate. Figure 5 shows the vertical and longitudinal displacement responses of the bridge under the excitation of $\mathrm{T}=0.22 \mathrm{~s}$ and $\mathrm{V} / \mathrm{H}=\lambda=0.9$. With an analysis interval of $2 \mathrm{~s}$, the girder and pier were separated five times. It can be seen that the pier and girder may be separated under the action of the near-fault earthquake. Figure $5 b$ shows that the separation of the pier and girder caused a significant change in the longitudinal displacement of the bridge. The maximum longitudinal relative displacement of the pier and girder increased from $14.9 \mathrm{~mm}$ to $31.8 \mathrm{~mm}$, an increase of $66.5 \%$.

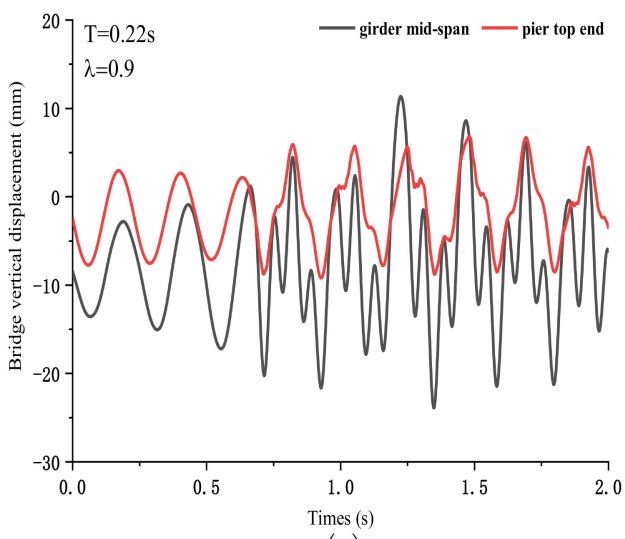

(a)

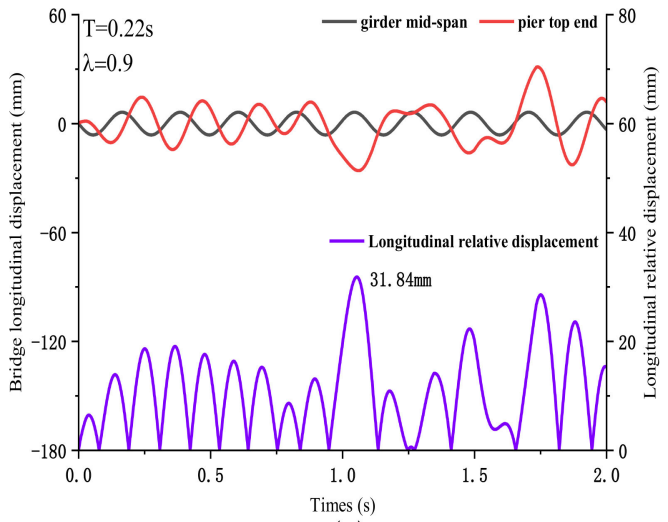

(b)

Figure 5. Bridge displacement response considering different separation conditions: (a) vertical displacement, and (b) longitudinal displacement.

Figure 6 shows the vertical contact force between the girder and pier under two excitation cycles. When $\mathrm{T}=0.35 \mathrm{~s}$, the vertical contact force between the girder and the pier was $21.57 \mathrm{MN}$, which is 1.75 times the static contact force; when $\mathrm{T}=0.22 \mathrm{~s}$, the vertical contact force between the main beam and the pier was $30.88 \mathrm{MN}, 2.56$ times the static contact force.

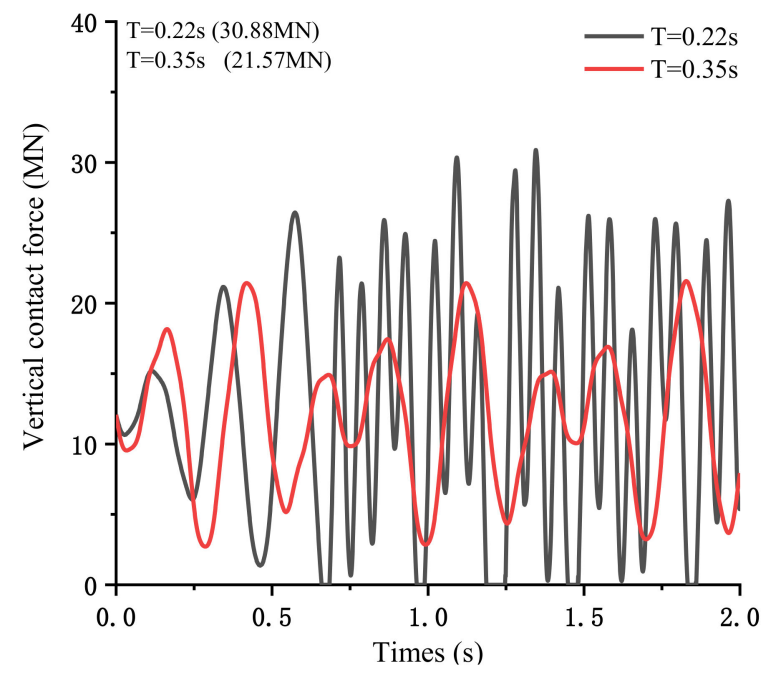

Figure 6. The vertical contact force of the bridge when $\mathrm{T}=0.22 \mathrm{~s}$ and $\mathrm{T}=0.5 \mathrm{~s}$.

When examining the effect of a longitudinal earthquake on the high-damping rubber bearing bridge, the damage appeared at the bottom of the pier. 
Under the action of an earthquake, the bending moment at the bottom of the pier mostly comes from the eccentric compression of the main girder, $\mathrm{M}_{\mathrm{c}}$, the bearing shear, $M_{v}$, and the forced vibration of the pier, $M_{z}$. The specific stress diagram is shown in Figure 7 .

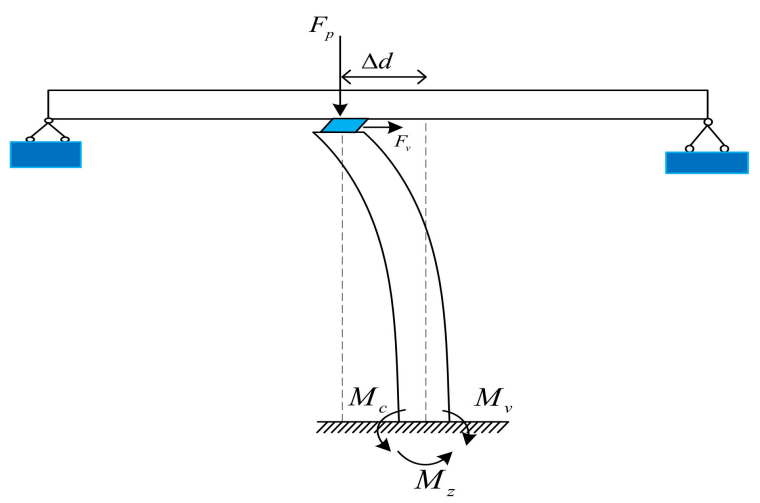

Figure 7. Schematic diagram of the bending moment at the bottom of the pier.

Due to the time difference between the vertical seismic wave and the longitudinal seismic wave, to consider the most unfavorable pier damage the bending moment generated by the vertical collision force can be calculated by $M_{c}=F_{\text {max }} \times \eta \times \Delta d$, where $F_{\text {max }}$ is the maximum vertical contact force, $\Delta \mathrm{d}$ is the maximum longitudinal relative displacement of the pier and girder, and $\eta$ is the amplification factor of eccentric impact (for the specific calculation, refer to [24]). The bending moment produced by the bearing shear force was calculated by $M_{v}=K_{v} \times \Delta d \times L$. The bending moment generated by the vibration of the pier was $M_{z}=E_{r} I_{r} \partial^{2} U_{d} / \partial \xi^{2}$. Figure 8 shows the magnitude of the bending moment on the bottom of the pier when $\mathrm{T}=0.35 \mathrm{~s}$ and $\mathrm{T}=0.22 \mathrm{~s}$ (if the separation is ignored, the vertical force is twice the static contact force). Based on the calculation, it can be concluded that, since the vertical natural vibration period of the bridge is far from the longitudinal natural vibration period, when the seismic excitation period, $T$, is close to the bridge, $T_{v}$, the separation of the pier and girder is ignored, the bending moment on the bottom of the pier is small, and the pier is safe (the total bending moment is below the allowable bending moment). When the seismic excitation period, $\mathrm{T}$, was close to the bridge, $T_{s}$, the longitudinal relative displacement of the pier and girder was relatively large and excessive $M_{z}$ caused bending failure of the base of the pier. When $T$ was close to $T_{v}$, and considering the separation of pier and beam, the bottom of the pier suffers bending damage, and the damage amplitude is the largest of the three cases considered.

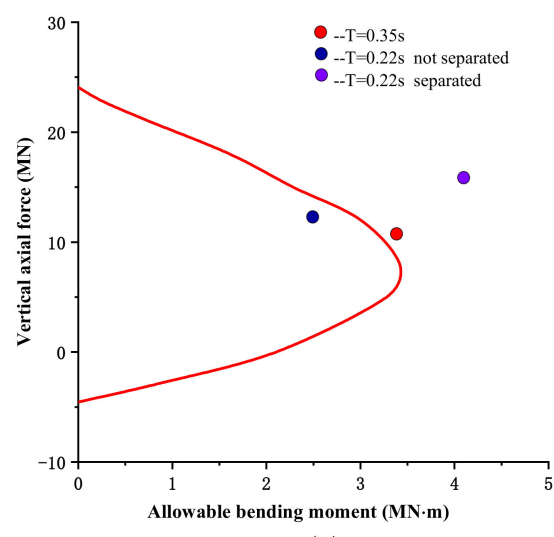

(a)

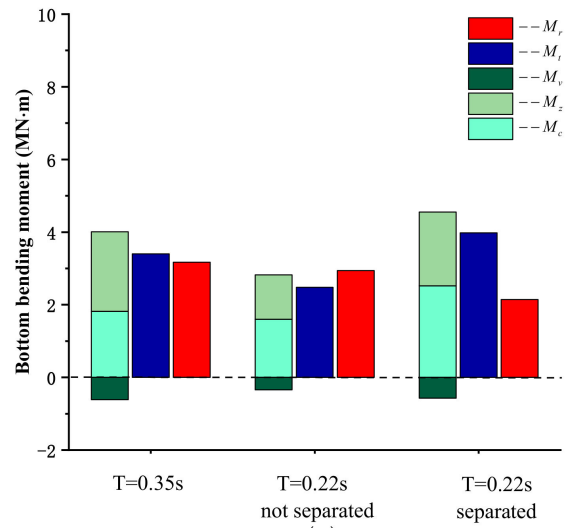

(b)

Figure 8. Bending moment at the base of the pier: (a) total bending moment and allowable bending moment of the base of the pier during two periods; and (b) the direction and magnitude of various bending moments at the base of the pier. 
This situation arose because when $T$ is close to $T_{v}$, the pier and beam produce a larger vertical contact force, and the longitudinal relative displacement increases when separation is considered, so $M_{c}$ has a larger increase than when $T \approx T_{s}$. Moreover, the greater vertical force reduces the allowable bending moment of the pier. The calculation result is shown in Figure 8 . When $T \approx T_{v}$, ignoring the pier-beam separation may incorrectly estimate the pier-girder relative longitudinal displacement response, thus underestimating the damage to the pier caused by an earthquake. In Figure $8, M_{t}$ is the total bending moment and $M_{r}$ is the allowable bending moment.

\subsection{The Influence of the Height of the Pier on the Damage of the Pier's Base}

Since the height of the bridge's pier has little effect on the vertical natural vibration frequency of the bridge, we assumed that changes to the pier height did not affect the vertical natural frequency of the bridge, and that only the longitudinal natural frequency changed. Table 2 shows the longitudinal natural frequency of the bridge at different pier heights.

Table 2. Longitudinal natural frequency of the bridge at different heights.

\begin{tabular}{cccc}
\hline $\begin{array}{c}\text { Pier Height } \\
\mathbf{H} / \mathbf{m}\end{array}$ & $\begin{array}{c}\text { Natural Vibration } \\
\text { Period } \mathbf{T}_{\mathbf{s}} / \mathbf{s}\end{array}$ & $\begin{array}{c}\text { Pier Height } \\
\mathbf{H} / \mathbf{m}\end{array}$ & $\begin{array}{c}\text { Natural Vibration } \\
\text { Period } \mathbf{T}_{\mathbf{s}} / \mathbf{s}\end{array}$ \\
\hline 5 & 0.036 & 13 & 0.252 \\
7 & 0.070 & 15 & 0.336 \\
9 & 0.121 & 17 & 0.431 \\
11 & 0.181 & 19 & 0.539 \\
\hline
\end{tabular}

Figure 9 shows the relative longitudinal displacement of the pier and girder at different pier heights when $T \approx T_{S}$ and $T \approx T_{v}$. When $T \approx T_{S}$, as the height of the pier increases, the longitudinal relative displacement of the pier and girder increases monotonically. When $T \approx T_{v}$, the bridge's longitudinal displacement response differs greatly depending on whether separation is considered. When ignoring separation, as the height of the pier increases, the longitudinal relative displacement gradually increases, there is a peak at $T_{v} \approx T_{s}$, and the maximum relative displacement gradually decreases after reaching the peak. When considering separation, the longitudinal relative displacement of the pier and girder has a peak value at $T_{v} \approx T_{s}$, followed by a slight decrease before continuing to increase as the height of the pier increases.

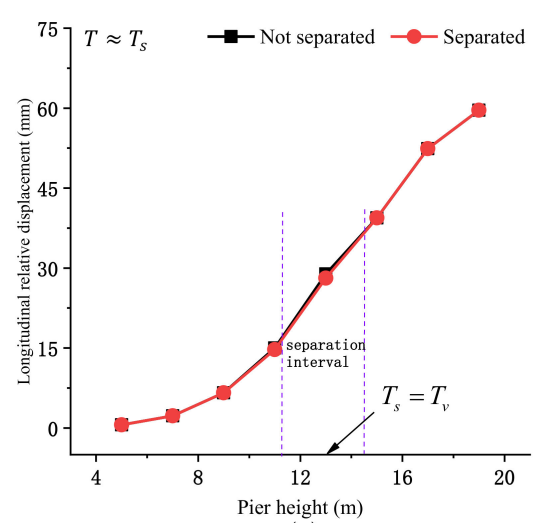

(a)

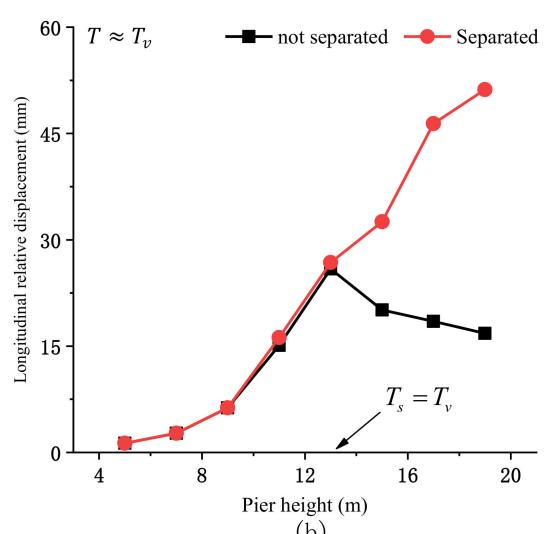

(b)

Figure 9. Longitudinal displacement at different pier heights: (a) maximum longitudinal relative displacement of girder and pier when $T \approx T_{s} ;(\mathbf{b})$ maximum longitudinal relative displacement of girder and pier when $T \approx T_{v}$.

Figure 10 shows the variation of various bending moments with the height of the pier. When $T \approx T_{S}$, the bending moment generated by the bearing shear increased monotonically. 
The bending moment caused by eccentric compression gradually increased with the height of the pier. The bending moment produced by the vibration of the bridge pier first increased and then went almost unchanged with the increase of pier height. When separation was considered, there was an obvious peak near $T_{v}=T_{s}$.

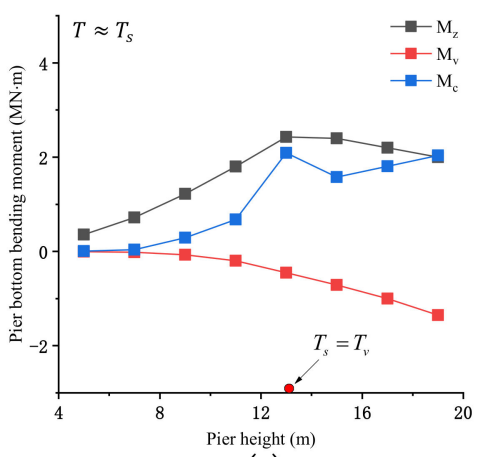

(a)

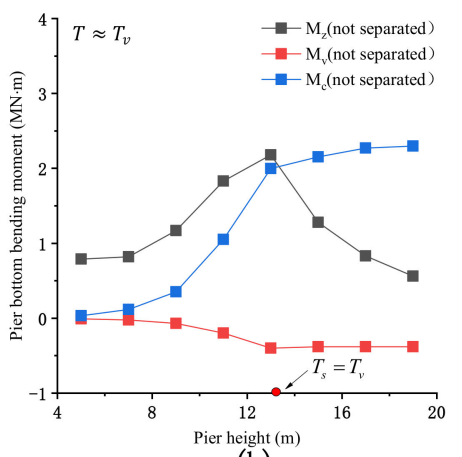

(b)

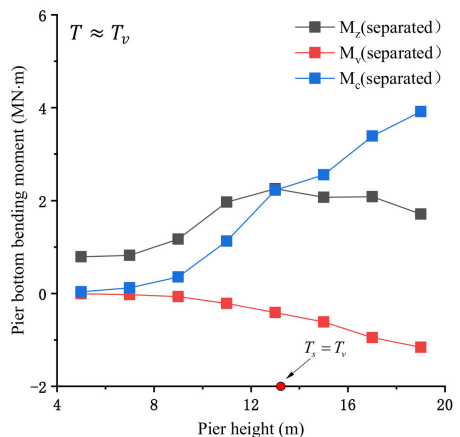

(c)

Figure 10. Calculated values of the base of the pier's bending moment at different pier heights: (a) the values of bending moments when $T \approx T_{s} ;(\mathbf{b})$ ignoring the values of bending moments under separation conditions when $T \approx T_{v}$; (c) considering the values of bending moments under separation conditions when $T \approx T_{v}$.

When $T \approx T_{v}$, ignoring the separation of the piers and main girder, the bending moment generated by the bearing shear increased slightly near $T_{v}=T_{s}$ and then remained stable. When considering the separation of the piers from the main girder, the relative displacement gradually increased.

The bending moment generated by the vibration of the bridge pier had a peak near $T_{v}=T_{s}$ and then showed a downward trend, but the bending moment was larger when considering separation. For the bending moment caused by eccentric compression, there was only a slight difference if separation was considered or not. When separation was ignored, the bending moment increased first and then decreased slightly. When separation was considered, the height of the pier increased approximately monotonically.

Figure 11 shows the calculation results of the total bending moment at the bottom of the pier and the allowable bending moment of the pier at different pier heights. When $\mathrm{T} \approx \mathrm{T}_{\mathrm{s}}$, the total bending moment at the bottom of the pier first increased but then decreased with the increase of the height of the pier. When separation was considered, the peak value of the total bending moment was greater and the allowable bending moment was generally stable. However, when $T_{v} \approx T_{S}$, the allowable bending moment was lower.

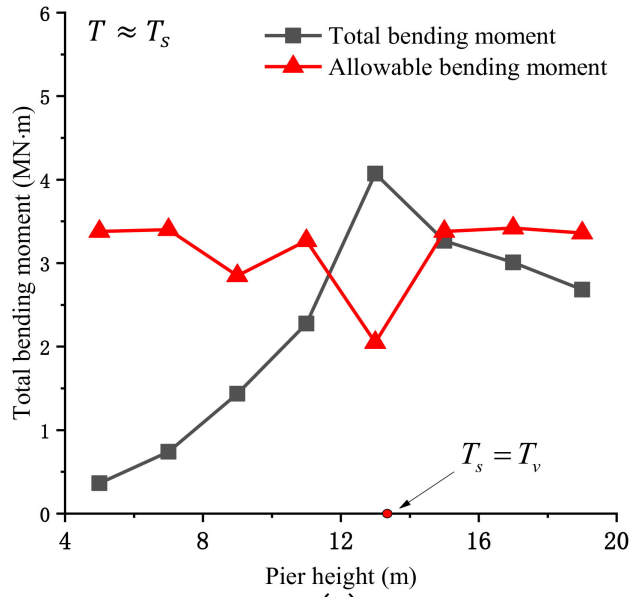

(a)

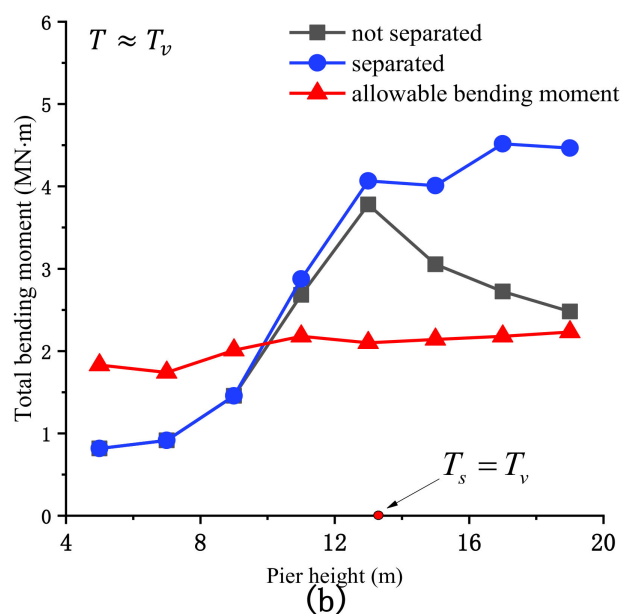

(b)

Figure 11. The destruction of the bottom of the pier at different pier heights: (a) total bending moment and allowable bending moment of the pier's base when $T \approx T_{s} ;(\mathbf{b})$ total bending moment and allowable bending moment of pier's base when $T \approx T_{v}$. 
When ignoring separation, the total bending moment at the bottom of the pier had a peak near $T_{v}=T_{S}$, which was due to the increase in the longitudinal relative displacement of the pier and the girder due to resonance. As the height of the bridge pier increased, the total bending moment at the bottom of the pier gradually decreased and gradually entered a safe range. However, when considering separation, there was a peak in the total bending moment at the bottom of the pier near $T \approx T_{v}$, and the value greatly exceeded that when separation was ignored. The total bending moment at the bottom of the pier fluctuated with the height of the pier, but all values exceeded the allowable bending moment. Thus, ignoring the separation of piers from the girder will lead to an underestimation of the failure of the bottom of the pier.

\subsection{The Influence of Pier Diameter on Pier Base Damage}

Like the change in the height of the bridge pier, the change in the diameter of the pier has little effect on the vertical vibration frequency of the bridge. In the calculation process we used, the influence of the pier section size on the vertical natural frequency of the bridge was ignored. Table 3 shows the longitudinal vibration frequencies of the bridge under different pier diameters.

Table 3. Longitudinal natural vibration frequencies of bridges under different diameters.

\begin{tabular}{cccc}
\hline $\begin{array}{c}\text { Pier Diameters } \\
\mathbf{H} / \mathbf{m}\end{array}$ & $\begin{array}{c}\text { Natural Vibration } \\
\text { Period } \mathbf{T}_{\mathbf{s}} / \mathbf{s}\end{array}$ & $\begin{array}{c}\text { Pier Diameters } \\
\mathbf{H} / \mathbf{m}\end{array}$ & $\begin{array}{c}\text { Natural Vibration } \\
\text { Period } \mathbf{T}_{\mathbf{s}} / \mathbf{s}\end{array}$ \\
\hline 1.0 & 0.403 & 1.4 & 0.288 \\
1.1 & 0.366 & 1.5 & 0.267 \\
1.2 & 0.336 & 1.6 & 0.252 \\
1.3 & 0.31 & 1.7 & 0.237 \\
\hline
\end{tabular}

We kept the height of the pier at $15 \mathrm{~m}$ and varied the pier diameter from 1 to $2 \mathrm{~m}$ to examine the effect of altering the pier diameter. The vertical natural vibration period of the bridge did not coincide with the longitudinal natural vibration period, so when the seismic excitation period was $T \approx T_{S}$, the girder and the pier would not have separated. As the pier diameter increased, the relative longitudinal displacement of the pier and girder decreases monotonically (Figure 12b). When the seismic excitation period was $T \approx T_{v}$, the relative longitudinal displacement of the pier and beam changed in the opposite direction depending on whether or not separation was considered (Figure 12a). When the separation was ignored, the relative longitudinal displacement of the pier and girder increased monotonically. This occurred because as the pier diameter increased, the longitudinal natural frequency of the bridge gradually approached the vertical natural frequency, and the longitudinal resonance effect gradually increased. When separation was considered, the longitudinal relative displacement of the pier and girder gradually decreased with the increase in diameter. Since the natural frequency of the pier gradually increased with increased pier diameter, the displacement amplitude of the pier following separation gradually decreased.

Figure 13 shows the changes in the bending moments at the bottom of the pier under different pier diameters when the seismic excitation period, $\mathrm{T}$, was close to $T_{S}$ and $T_{v}$. When the seismic excitation period was $T \approx T_{s}$, the bending moment generated by the vertical contact force of the pier beam and the bending moment generated by the support shear decreased monotonically because the longitudinal displacement reduces the bending moment. Since increase of $\mathrm{M}_{\mathrm{z}}$ is due to the increase of mass. When the seismic excitation period was $T \approx T_{v}$, the changing trends of various bending moments at the bottom of the pier were basically the same regardless of whether separation was considered. As separation increased the longitudinal relative displacement of the pier from the girder, the bending moment generated by the vibration of the pier increased compared to the extreme value when separation was ignored. 


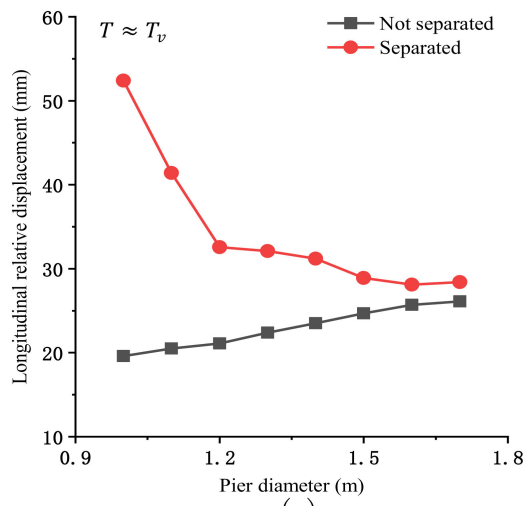

(a)

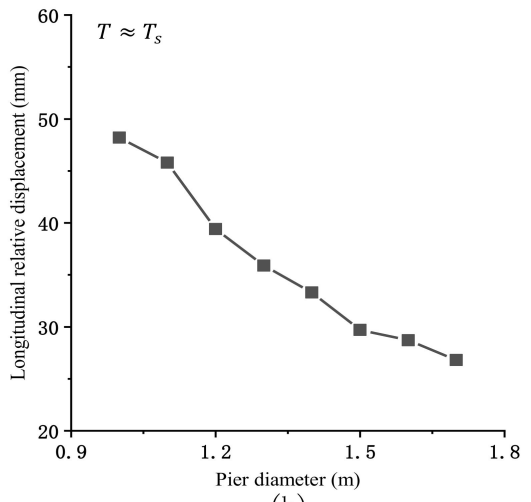

(b)

Figure 12. Longitudinal displacement of the pier and main girder with different pier diameters: (a) maximum relative longitudinal displacement of girder and pier when $T \approx T_{S}$; (b) maximum relative longitudinal displacement of girder and pier when $T \approx T_{v}$.

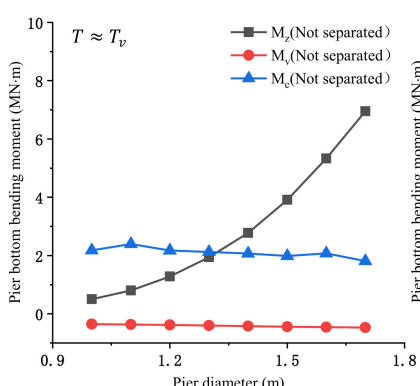

(a)

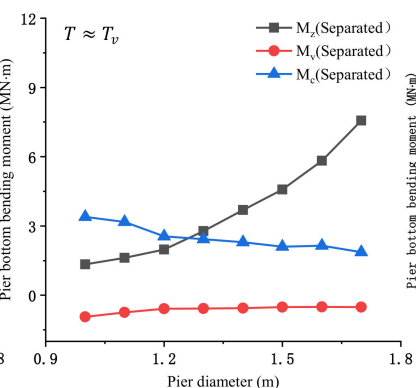

(b)

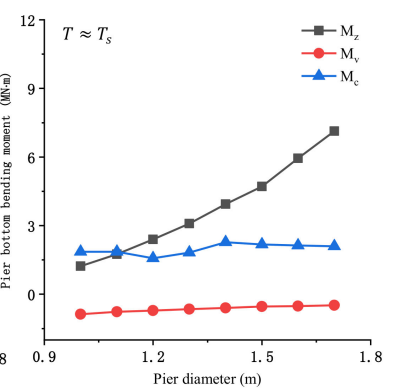

(c)

Figure 13. Bending moment at the base of the pier with different pier diameters: (a) the value of bending moments when separation was ignored at $T \approx T_{s} ;(\mathbf{b})$ the value of bending moments when separation was considered at $T \approx T_{s}$; and (c) the value of bending moments at $T \approx T_{v}$.

Figure 14 shows the total and allowable bending moments at the base of the pier with different pier diameters. When $T \approx T_{S}$, as the diameter of the pier increased the total bending moment at the base of the pier and the allowable bending moment of the pier increased. Moreover, the increase of the total bending moment exceeded the allowable bending moment, and the bending damage at the base of the pier gradually increased with increasing pier diameter. A similar trend was observed when $T \approx T_{v}$.

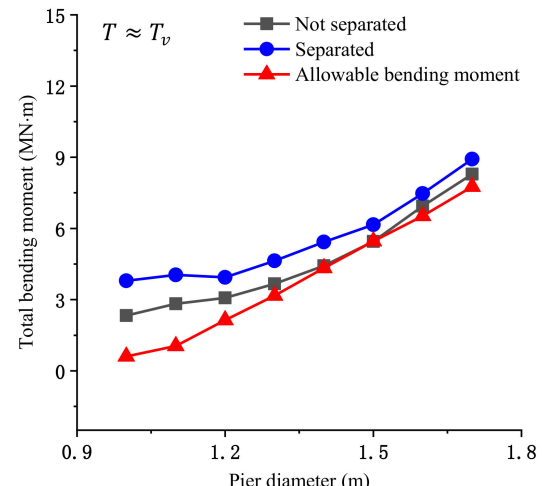

(a)

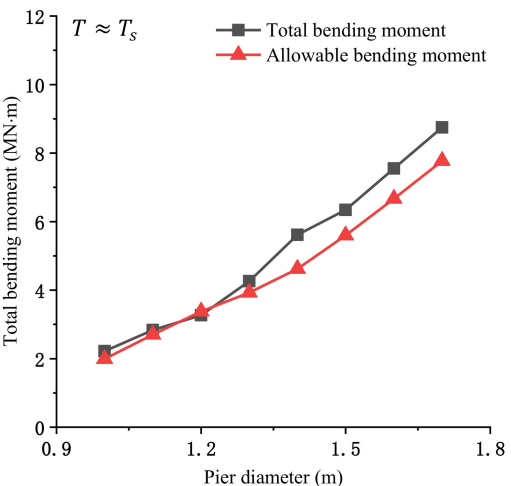

(b)

Figure 14. Failure at the base of the pier with different diameters: (a) Total bending moment and allowable bending moment at the base of the pier when $T \approx T_{s}$; (b) total bending moment and allowable bending moment at the base of the pier when $T \approx T_{v}$. 


\subsection{Results and Discussion}

Considering the effect of multiple separation of the double-span continuous girder in the vertical direction on the bending failure of the bottom of the pier, our analysis indicated the following:

1. When including vertical separation, the longitudinal displacement of the girder and piers changed significantly. The pier damage under high-amplitude vertical seismic excitation was not only concentrated in the $T \approx T_{s}$ interval: When $T \approx T_{v}$, the vertical direction of the bridge can separate, changing the displacement response of the bridge in the longitudinal direction, and the resultant increased relative displacement of the pier to the girder may cause damage to the pier.

2. With increased pier height, the maximum damage of the pier under the two excitation cycles of $T \approx T_{S}$ and $T \approx T_{v}$ is concentrated in the interval of $T_{\mathcal{V}}=T_{S}$, and the potential damage is greater. Moreover, when the seismic excitation period is $T \approx T_{v}$, the ratio of the bending moment generated by the vertical eccentric collision to the combined bending moment gradually increases with bridge pier height.

3. When the cross-sectional diameter of the pier increases, the relative displacement of the pier to the girder in the longitudinal direction changes slowly when $T \approx$ $T_{v}$ (ignoring separation). As the diameter increases, the bending moment at the bottom of the pier increases until it fails. In the two cases of $T \approx T_{\mathcal{V}}$ (including separation) and $T \approx T_{S}$, the increase in diameter greatly increases the bending moment caused by the vibration of the pier. Although the maximum relative displacement of the pier and the girder decreases with increased cross-sectional diameter, the pier was always in the failure zone in the study interval and the damage gradually worsened with increased diameter of the pier.

4. When $T \approx T_{v}$, separation affects the damage caused to the pier. As the height of the pier increases, the main damage is the bending moment caused by the eccentric collision, while as the diameter increases, the damage is caused by the vibration of the pier.

\section{Conclusions}

In this study, we explored the influence of the height and diameter of a bridge's pier on the damage caused to the pier under the action of a near-fault vertical earthquake. To this end, we established a girder-spring-damping-rod model: using the transient wave function expansion method and the indirect wave modal function method, the vertical and longitudinal contact force and displacement responses of the bridge were derived. Based on the comparison of the combined bending moment and the allowable bending moment of the three external forces acting on the bottom of the pier, we theoretically solved the two different excitation cycles of $T \approx T_{S}$ and $T \approx T_{v}$. In this study, we only considered the coupling in the longitudinal direction. In future work, we plan to consider the influence of the separation of the main girder and pier in both the transverse and longitudinal directions. The influence of structural separation on the collision between the main girder and the retaining block should also be considered when the retaining block is set horizontally for the limit of the bridge.

Author Contributions: Conceptualization, W.A. and G.S.; methodology, W.A.; software, W.A.; validation, W.A.; G.S., and S.C.; formal analysis, W.A. and G.S.; investigation, W.A.; resources, W.A.; data curation, G.S.; writing—original draft preparation, W.A.; writing—review and editing, W.A.; visualization, W.A.; supervision, G.S.; project administration, G.S.; funding acquisition, G.S. All authors have read and agreed to the published version of the manuscript.

Funding: APC was funded by Science and Technology Project of Jiangxi Provincial Education Department (GJJ202908).

Institutional Review Board Statement: Not applicable.

Informed Consent Statement: Not applicable. 


\section{Data Availability Statement: Not applicable.}

Conflicts of Interest: The authors declare no conflict of interest.

\section{References}

1. Li, H.; Xiao, S.; Huo, L. Damage investigation and analysis of engineering stuctures in the Wenchuan earthquake. J. Build. Struct. 2008, 29, 10-19.

2. Zhuang, W.; Liu, Z.; Jiang, J. Earthquake-induced damage analysis of highway bridges in Wenchuan earthquake and countermeasures. Chin. J. Rock Mech. Eng. 2009, 28, 1377-1387.

3. Xu, S.Y.; Zhang, J. Axial-shear-flexure interaction hysteretic model for RC columns under combined actions. Eng. Struct. 2012, 34, 548-563. [CrossRef]

4. Ghannoum, W.M.; Mohle, J.P. Rotation-Based Shear Failure Model for Lightly Confined RC Columns. J. Struct. Eng. 2012, 138, 1267-1278. [CrossRef]

5. Elwood, K.J. Modeling failures in existing reinforced concrete. Can. J. Civ. Eng. 2004, 31, 846-859. [CrossRef]

6. Cimellaro, G.P.; Domaneschi, M.; Warn, G. Three-Dimensional base isolation using vertical negative stiffness devices. J. Earthq. Eng. 2020, 24, 2004-2032. [CrossRef]

7. De Mari, G.; Domaneschi, M.; Ismail, M.; Martinelli, L.; Rodellar, J. Reduced-order coupled bidirectional modeling of the Roll-N-Cage isolator with application to the updated bridge benchmark. Acta Mech. 2015, 226, 3533-3553. [CrossRef]

8. Button, M.R.; Cronin, C.J.; Mayes, R.L. Effect of Vertical Motions on Seismic Response of Highway Bridges. J. Struct. Eng. 2002, 128, 1551-1564. [CrossRef]

9. Wilson, T.; Chen, S.; Mahmoud, H. Analytical case study on the seismic performance of a curved and skewed reinforced concrete bridge under vertical ground motion. Eng. Struct. 2015, 100, 128-136. [CrossRef]

10. Kunnath, S.K.; Erduran, E.; Chai, Y.H.; Yashinsky, M. Effect of near-fault vertical ground motions on seismic response of high overcrossings. J. Bridge Eng. 2008, 13, 282-290. [CrossRef]

11. Yu, C.P. Effect of Vertical Earthquake Components on Bridge Response. Ph.D. Thesis, University of Texas at Austin, Austin, TX, USA, 1998.

12. Papazoglou, A.J.; Elnashai, A.S. Analytical and field evidence of the damaging effect of vertical earthquake ground motion. Earthq. Eng. Struct. Dyn. 1996, 25, 1109-1137. [CrossRef]

13. Varecac, D.; Draganic, H.; Gazic, G. Influence of the Vertical Component of Earthquake on Large Span Rc Beams. Teh. Vjesn. -Tech. Gaz. Gaz. 2010, 17, 357-366.

14. Kim, S.J.; Holub, C.J.; Elnashai, A.S. Experimental investigation of the behavior of RC bridge piers subjected to horizontal and vertical earthquake motion. Eng. Struct. 2011, 33, 2221-2235. [CrossRef]

15. Kim, S.J.; Holub, C.J.; Elnashai, A.S. Analytical Assessment of the Effect of Vertical Earthquake Motion on RC Bridge Piers. J. Struct. Eng. -ASCE 2011, 137, 252-260. [CrossRef]

16. Wang, Z.; Dueñas-Osorio, L.; Padgett, J.E. Seismic response of a bridge-soil-foundation system under the combined effect of vertical and horizontal ground motions. Earthq. Eng. Struct. Dyn. 2013, 42, 545-564. [CrossRef]

17. Bozorgnia, Y.; Niazi, M.; Campbell, K.W. Characteristic of free-field vertical ground motion during the Northridge earthquake. Earthq. Spectra 1995, 11, 15-526. [CrossRef]

18. Wang, G.-Q.; Zhou, X.-Y.; Zhang, P.-Z.; Igel, H. Characteristics of amplitude and duration for near fault strong ground motion from the 1999 Chi-Chi, Taiwan earthquake. Soil Dyn. Earthq. Eng. 2002, 22, 73-96. [CrossRef]

19. Wang, D.; Xie, L. Attenuation of peak ground accelerations from the great Wenchuan earthquake. Earthq. Eng. Eng. Vib. 2009, 8, 179-188. [CrossRef]

20. Wang, C.J.; Shih, M.H. Performance study of a bridge involving sliding decks and pounded abutment during a violent earthquake. Eng. Struct. 2007, 29, 802-812. [CrossRef]

21. Ye, Z.; Guangjun, S.; Hongjing, L. Comparison and Research of Unseating Prevention Measures in Seismic Codes of China and Foreign Countries. J. Disaster Prev. Mitig. Eng. 2016, 36, 617-623, 639.

22. Wenfeng, H.; Chang, S.; Qingguo, L. Strong ground motion at meizoseisal area \& safety of important engineering projects at potential earthquake region. J. Eng. Geol. 2004, 12, 346-353.

23. Tanimura, S.; Mimura, K.; Nonaka, T.; Wenhui, Z.H.U. Dynamic failure of structures due to the great Hanshin-Awaji earthquake. Int. J. Impact Eng. 2000, 24, 583-596. [CrossRef]

24. Yang, H.; Yin, X.; Hao, H.; Bi, K. Theoretical Investigation of Bridge Seismic Responses with Pounding under Near-Fault Vertical Ground Motions. Adv. Struct. Eng. 2015, 18, 452-468. [CrossRef]

25. Yufeng, X.; Lijuan, W. Analysis of wave propagation in the built-up structures of rod-beam and beam-beam. J. Beijing Univ. Aeronaut. Astronaut. 2013, 30, 520-523.

26. Ministry of Housing and Urban-Rural Development of the People's Republic of China. CJJ 166-2011. Code for Seismic Design of Urban Bridges; Ministry of Housing and Urban-Rural Development of the People's Republic of China: Beijing, China, 2011.

27. Bozorgnia, Y.; Campbell, K.W. The Vertical -to-horizontal response spectral ratio and Entative procedures for developing simplified V/H and vertical design spectra. J. Earthq. Eng. 2004, 8, 175-207. [CrossRef] 